East African Medical Journal Vol. 85 No. 3 March 2008

MOLECULAR TECHNIQUE UTILISING SPUTUM FOR DETECTING WUCHERERIA BANCROFTI INFECTIONS IN MALINDI, KENYA

J. M. Kagai, MSc, Senior Research Officer, S. Mpoke, PhD, Chief Research Officer, Kenya Medical Research Institute, P.O. Box 54840-00200, Nairobi, Kenya, F. Muli, PhD, Senior Lecturer, Department of Biotechnology and Biochemistry, Kenyatta University, P.O. Box 43844-00100 Nairobi, Kenya, J. Hamburger, PhD, Professor, Hadassah Medical School, Hebrew University, P.O. Box 12272, Jerusalem 91120 Israel and E. U. Kenya, PhD, Senior Lecturer, Kenyatta University, P.O. Box 43844-00100, Nairobi, Kenya

Request for reprints to: Mr. J. M. Kagai, Senior Research Officer, Kenya Medical Research Institute, P.O. Box 54840-00200, Nairobi, Kenya

\title{
MOLECULAR TECHNIQUE UTILISING SPUTUM FOR DETECTING WUCHERERIA BANCROFTI INFECTIONS IN MALINDI, KENYA
}

\author{
J. M. KAGAI, S. MPOKE, F. MULI, J. HAMBURGER and E. U. KENYA
}

\begin{abstract}
Background: Lymphatic filariasis is a tropical parasitic disease which has been identified for elimination by 2020 through mass drugs administration. There is a major problem in its diagnosis and sensitive surveillance methods for monitoring the disease elimination programs need to be sought.

Objectives: To establish and evaluate the usefulness of a Polymerase Chain Reaction, PCR assay employing sputum for diagnosis of Wuchereria bancrofti infections in an endemic location.

Design: Community based samples collection and a molecular laboratory technologies study.

Setting: Mpirani, Malindi District and Centre for Biotechnology Research and Development, Kenya Medical Research Institute.

Subjects: Sputum samples were obtained from 304 willing and consenting participants, aged between 5 and 73 years resident in Mpirani, Malindi District.

Results: Prevalence of $W$. bancrofti infection was found to be $42.8 \%(130 / 304)$ by PCR assay employing sputum compared with $22.0 \%(67 / 304)$ and $38.8 \%(119 / 304)$ respectively for microfilaria counts and ICT. The sensitivity and specificity of the PCR sputum assay was 97.5 and $92.4 \%$ respectively. Predictive values were 89.2 and $98.3 \%$ for positive (PPV) and negative (NPV) respectively while accuracy was $94.4 \%$.

Conclusions: The molecular PCR assay using sputum was found to have a great potential for use in mass diagnosis and in epidemiological studies in patients with $W$. bancrofti infections
\end{abstract}

\section{INTRODUCTION}

Lymphatic filariasis is a tropical disease caused by the parasitic worms Wuchereria bancrofti, Brugia malayi or B. timori (1). Ninety per cent of lymphatic filariasis infections are caused by W. bancrofti. The life cycle of these parasites oscillate between humans and the vector mosquito. Wuchereriabancrofti has a nocturnal periodicity, where the microfilariae appear in the peripheral blood of a patient at night between $10.00 \mathrm{pm}$ and $02.00 \mathrm{am}$. During the other times, however, microfilariae can be found in the lungs, where the oxygen tension ishigh. Althoughlymphatic filariasis has low mortality, it is a major cause of clinical morbidity and disability. Of the 120 million infected persons in 80 tropical countries, 44 million display overt symptoms such as the swelling of limbs and genitalia (2). World Health Organization (WHO) initiated a Global Program for Elimination of Lymphatic Filariasis, (GPELF) by mass treatment of the infected and those-at-risk, estimated at 1.1 billion (2). Research is needed to identify and evaluate techniques for rapid assessment and mapping of the disease and to develop mechanisms for surveillance 
and for monitoring the effectiveness of interventions (3). We report results of an evaluation of the sputum PCR assay using samples obtained from individuals living in an endemic locality in coastal Kenya.

\section{MATERIALS AND METHODS}

Study population and specimen collection: Sputum and blood samples were collected from 304 individuals living in the endemic locality of Mpirani in Malindi District Kenya (4). In this study we modified the method of Abassi et al (5) by using a different set of primers for detection of $W$. bancrofti infection in sputum. Willing and consenting participants who had lived in the study area for at least three years and were above the age of five years were included in the study. People who had not lived in the study area for the last three years were excluded from the study. Although sputum samples can be collected any time during the day or night, samples were collected between $10.00 \mathrm{pm}$ and $02.00 \mathrm{am}$ together with blood for microscopy. This is the time that the microfilariae of this nocturnal parasite can be found in the blood. All samples were collected between April and December, 2004.

Each individual was examined by a qualified clinician and requested to give sputum and blood. Approximately $1 \mathrm{ml}$ of sputum was collected from each participant in $0.1 \mathrm{M}$ ethylene-diamine tetra acetic acid (EDTA). When necessary, sputum was induced by a deep cough following a brief jogging or push-up exercise(5). Blood samplefor Immunochromatographic test (ICT), microfilariae examination and counts consisted of $1 \mathrm{ml}$ of venous blood collected in $0.1 \mathrm{M}$ EDTA $(6,7)$. The samplesize 304 was determined using the formula of Fischer et al (8).

Microfilariae counts and immunochromatographic tests (ICT): Blood samples were examined for presence of microfilariae by microscopy using the procedure recommended by McMahon et al, (1979) (7), where $100 \mu \mathrm{l}$ of patient's night blood was added to $900 \mu \mathrm{l}$ of $3 \%$ Acetic acid and examined under low power in a microscope, using a special chamber. All the microfilariae in the chamber were counted twice and recorded.

While performing the ICT, $100 \mu$ l of each blood sample were processed according to the manufacturer's instructions (Binax Inc. USA).

DNA Extraction and PCR amplification: Wuchereria bancrofti DNA from sputum was extracted as described by Abbasi et al. (5), with some minor modifications. For optimal thermocycling, the DNA was denatured at $94^{\circ} \mathrm{C}$ for five minutes, annealing at $54^{\circ} \mathrm{C}$ for one minute and elongation at $72^{\circ} \mathrm{C}$ for one minute. This was repeated for 35 cycles, before a further elongation step at $72^{\circ} \mathrm{C}$ for ten minutes. The primer pair used in this study, forward 5' CGTGATGGCATAAAGTAGCG 3' and reverse 3' CСТCACTTACCATAAGACAAC 5'), were originally designed by Zhong, et al. (9). They amplified $188 \mathrm{bp}$ fragment of $W$. bancrofti DNA sequence. The amplification products were separated by electrophoresis in $1.2 \%$ agarose gels against a $200 \mathrm{bp}$ DNA marker. The bands were visualised under UV light after staining with ethidium bromide and photographed for permanent record.

\section{RESULTS}

Microscopy, microfilariae (MF) counts and ICT: Of the 304 samples of sputum and blood, 126 were obtained from females and 178 males in the age range 5 - 73 years from five villages of Mpirani (Table 1). Microfilariae were observed in $22 \%(67 / 304)$ of the blood samples of the individuals examined. The counts ranged from one microfilaria to 866 microfilariae per millilitre of whole blood (Table 2). There were 237 samples without any microfilariae. Seven samples had counts ranging from 101 to 866 . When arranged according to age-groups (Table 3), there was a high prevalence in the age group 51-60 and the lowest in 5-10 group.

Table 1

Distribution of the study population among the five villages

\begin{tabular}{lccc}
\hline Village & Female & Male & Total \\
\hline Garashi & 18 & 21 & 39 \\
Madzayani & 58 & 93 & 151 \\
Majehazini & 24 & 31 & 55 \\
Mbaoni & 12 & 22 & 34 \\
Sabaki & 14 & 11 & 25 \\
\hline Total & 126 & 178 & 304 \\
\hline
\end{tabular}

Table 2

The distribution of microfilaria (MF) counts in the samples

\begin{tabular}{lc}
\hline $\begin{array}{l}\text { Microfilaria counts / } \mathrm{ml} \\
\text { of blood }\end{array}$ & $\begin{array}{c}\text { Number of } \\
\text { samples }\end{array}$
\end{tabular}

\begin{tabular}{lc}
\hline 0 & 237 \\
$1-10$ & 41 \\
$11-100$ & 19 \\
$101-866$ & 7 \\
\hline
\end{tabular}


Table 3

Total microfilaria (MF) counts according to age groups

\begin{tabular}{lccc}
\hline $\begin{array}{l}\text { Age group } \\
\text { (years) }\end{array}$ & $\begin{array}{c}\text { Total number } \\
\text { of samples }\end{array}$ & $\begin{array}{c}\text { Number positive by } \\
\text { MF counts }\end{array}$ & $\begin{array}{c}\text { Percentage of total } \\
\text { MF counts positive }\end{array}$ \\
\hline $5-10$ & 31 & 3 & 9.7 \\
$11-20$ & 121 & 19 & 15.7 \\
$21-30$ & 52 & 13 & 25.0 \\
$31-40$ & 31 & 11 & 35.5 \\
$41-50$ & 26 & 6 & 23.1 \\
$51-60$ & 27 & 10 & 37.0 \\
$61-73$ & 16 & 5 & 31.3 \\
\hline Total & 304 & 67 & 22.0 \\
\hline
\end{tabular}

A total of 119 out of 304 samples were found positive by ICT. This constituted $38.8 \%$ of the test samples with the highest number of positive cases among the 61-73 group who had $62.5 \%$ prevalence (Table 4 ). Positive cases among the age groups 51-60, 31-40, and $41-50$ years, were $51.9 \%, 51.6 \%$ and $50.0 \%$ respectively. Age groups 11-20 and 21-30 had a prevalence of $33.9 \%$ and $34.6 \%$ respectively. The lowest prevalence was found among the 5-10 year age group who had $22.6 \%$. Out of the 178 male population $71(39.9 \%)$ had positive results by ICT. The highest prevalence was among the 51-60 year age group, who had $76.9 \%(10 / 13)$ with the lowest being the 5-10 year age group showing a prevalence of $21.1 \%(4 / 19)$.
Polymerase chain reaction PCR assays results: Wuchereria bancrofti infection detected by PCR sputum assay was $42.8 \%$ (130/304) for all the age groups (Table 5). Among the age group 61-73 years there was a high number of positive cases $62.5 \%(10 / 16)$ followed by the age group $31-40$ with $58.1 \%$ (18/31), age group 41-50 with $57.7 \%$ and age group 51-60 with $51.9 \%$. Out of 52 samples in the age group 21-30, there were $21(40.4 \%)$ sputum PCR positive samples. Forty three samples $(35.5 \%)$ were sputum PCR positive in the age group 11-20 years, compared with $29.0 \%$ (9/ 31 ) in the age group 5-10 years, which had the lowest prevalence (Figure 1).

Table 4

Immunochromatographic test (ICT) results of the total test samples

\begin{tabular}{lccc}
\hline $\begin{array}{l}\text { Age group } \\
\text { (years) }\end{array}$ & $\begin{array}{c}\text { Total number of } \\
\text { samples }\end{array}$ & $\begin{array}{c}\text { Number positive } \\
\text { by ICT }\end{array}$ & $\begin{array}{c}\text { Percentage of } \\
\text { total ICT }\end{array}$ \\
\hline $5-10$ & 31 & 7 & 22.6 \\
$11-20$ & 121 & 41 & 33.9 \\
$21-30$ & 52 & 18 & 34.6 \\
$31-40$ & 31 & 16 & 51.6 \\
$41-50$ & 26 & 13 & 50.0 \\
$51-60$ & 27 & 14 & 51.9 \\
$61-73$ & 16 & 10 & 62.5 \\
\hline Total & 304 & 119 & 39.1 \\
\hline
\end{tabular}

Table 5

Polymerase chain reaction (PCR) assay for sputum in all samples according to age groups

\begin{tabular}{lccc}
\hline $\begin{array}{l}\text { Age group } \\
\text { (years) }\end{array}$ & $\begin{array}{c}\text { Total number of } \\
\text { samples }\end{array}$ & $\begin{array}{c}\text { Number of PCR } \\
\text { Positive samples }\end{array}$ & $\begin{array}{c}\text { Percentage of PCR } \\
\text { Positive }\end{array}$ \\
\hline $5-10$ & 31 & 9 & 29.0 \\
$11-20$ & 121 & 43 & 35.5 \\
$21-30$ & 52 & 21 & 40.4 \\
$31-40$ & 31 & 18 & 58.1 \\
$41-50$ & 26 & 15 & 57.7 \\
$51-60$ & 27 & 14 & 51.9 \\
$61-73$ & 16 & 10 & 62.5 \\
\hline Total & 304 & 130 & 42.8 \\
\hline
\end{tabular}


Figure 1

Percentage prevalence by sex and age in sputum PCR assay

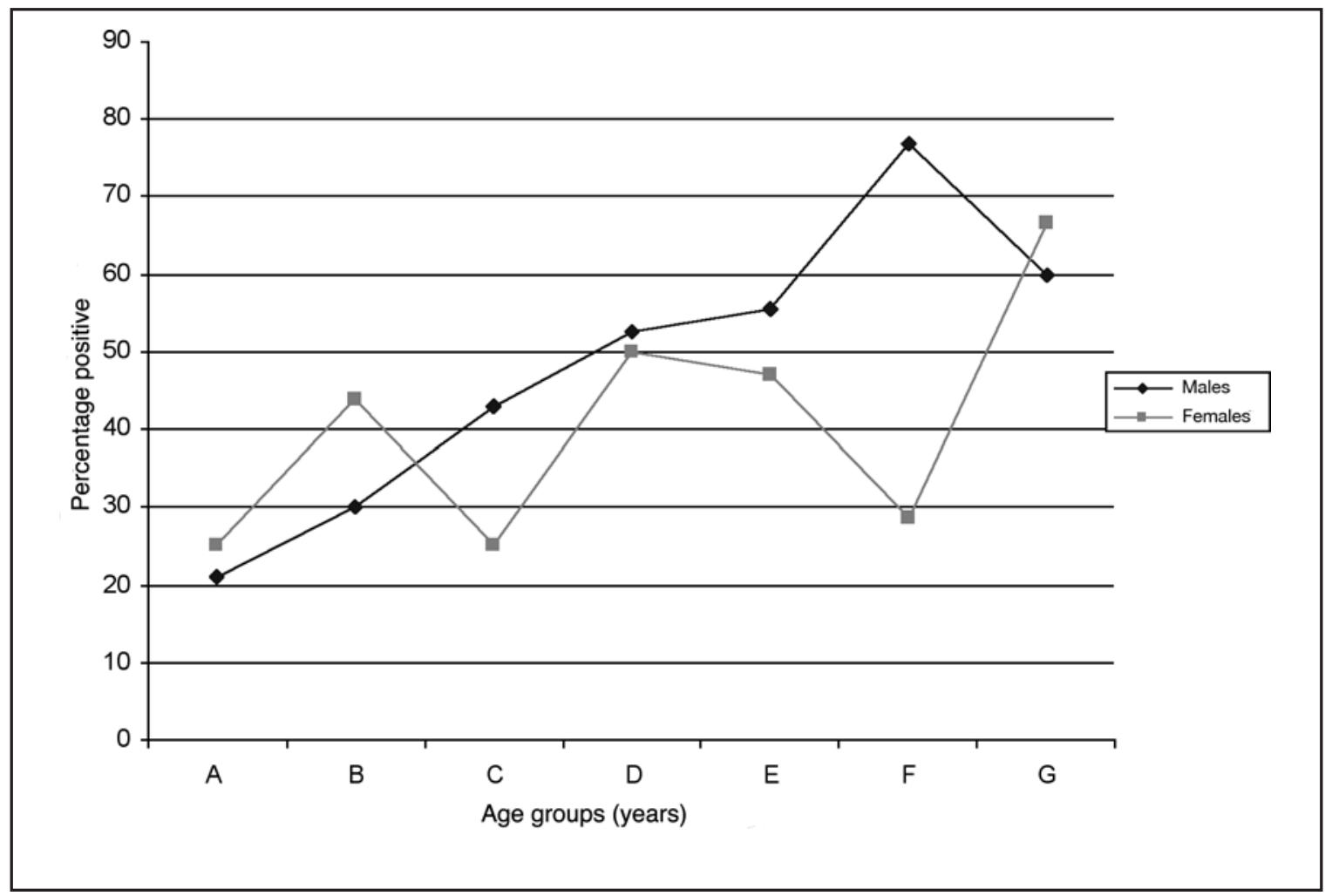

$A=5-10 ; B=11-20 ; C=21-30 ; D=31-40 ; E=41-50 ; F=51-60 ; G=61-73$ years

Seventy three males $(41.0 \%)$ were sputum PCR positive. There was high PCR prevalence among the age group 51-60 years with $69.2 \%$ (9/13). The other age groups; 61 $73,31-40,41-50$, and 21-30 followed with $60.0 \%, 57.9 \%$, $55.6 \%$ and $46.4 \%$, respectively. The lowest number of sputum PCR positive cases occurred in 11-20 year age group with $28.8 \%$ (23/80) followed by age group 5-10 years with $31.6 \%$. Prevalence among females was $66.7 \%$ (4/6) among the 61-73 year age group compared with 510 year group which was the lowest at $25.0 \%$ (3/12).

Validation of the PCR assay for sputum: Sensitivity and specificity for the PCR assay for sputum was performed as suggested by Greenhalgh(10). Sensitivity was defined as the ability of the PCR assays to identify $W$. bancrofti DNA in ICT positive samples. The sensitivity and specificity of the assay was 97.5 and $92.4 \%$, respectively, where, the positively identified samples were 116 out of 119 ICT positive samples.

Sensitivity, specificity, predictive values and accuracy: Positive predictive value (PPV) was defined as the ability of a positive PCR assay to indicate that the $W$. bancrofti DNA is present in a sample. Consequently, the Negative predictive value (NPV) was defined as the ability of a negative PCR assay to indicate W. bancrofti DNA was absent in the negative sample. Using a formula suggested by Greenhalgh (10), the PPV for PCR assay for sputum was found to be $89.2 \%$ and NPV $98.3 \%$. Accuracy of the PCR assay was defined as the proportion of all tests that gave the correct result as compared with ICT. The accuracy of PCR assay for sputum was $94.4 \%$.

Quality control: Gel electrophoresis was repeated thrice for all samples. Any sample showing a band in two of theelectrophoresis runs was taken to be positive. Further, thirty samples constituting $9.87 \%$ (30/304) of the study group were selected by picking randomly fifteen positive and fifteen negative PCR assay and performing ${ }^{35} \mathrm{~S}$ dot blot hybridisation. Positive results were determined by appearance of black dots on the photographic film. There was $100 \%$ concordance, indicating that in all these representative samples all the 15 PCR positive samples had the specific $W$. bancrofti DNA, while the negative samples did not have the specific $W$. bancroft $i$ DNA.

\section{DISCUSSION}

The present study examined $W$. bancrofti infections in Mpirani, Malindi District, Kenya using a PCR assay that uses sputum and compared the results obtained to ICT and microfilariae counts. By using ICT as the standard, the assay employed in this study was both sensitive and specific with values around $90 \%$. The assay had the highest prevalence $(42.8 \%)$ compared to ICT $(38.8 \%)$ and microscopy $(22.0 \%)$. Prevalence increased gently with age (Figure 1) and although the results did not show any statistical differences, the males seemed to 
show a higher prevalence than females. There were 11 positive samples by PCR, but negative by ICT. All the 11 samples however, had 0 to 10 microfilaria counts per $\mathrm{ml}$, for which ICT may have missed because it has low sensitivity $(11,12)$. The advantages of the PCR assay used in this study include high sensitivity, specificity and demonstrated a high accuracy value of $94.4 \%$. This was coupled with commendable ease of sample collection. By using PCR assay that utilise sputum, there are reduced risks of infection with the blood borne infectious diseases such as HIV/AIDS and hepatitis (13) as in deed a study by Marcus, (14) did demonstrate that $0.3 \%$ of health workers can get infected by HIV / AIDS if exposed.

Community co-operation is essential in disease elimination efforts, such as the one underway for lymphatic filariasis (2). Local people can be shown how to collect sputum samples and transport them to a central laboratory thus enhancing the communal participation and solving most the logistical problems encountered by visiting medical teams such as access to areas that cannot otherwise be reached by vehicles (15).

The cost of performing PCR assays remains high due to various reagents and equipments. Several researchers have suggested pooling of samples in mass diagnosis and epidemiological studies. Abbasi et al., were able to pool 14 negative samples with one positive sample and were able to detect the $W$. bancrofti DNA (5). We suggest further studies in this areas, as a way of reducing cost of performing PCR assays. Pooling of samples by house hold for instance may, reduce costs of PCR assays probably by up to $90 \%$ as average house holds in Mpirani has an average of ten persons. Malhotra et al., and Weerasooriya, et al., had shown a higher prevalence of $W$. bancrofti infection among children whose parents were infected $(16,17)$. This would mean increased chances of patients capture among the households with $W$. bancrofti infections in a pooled sample. The positive households could then benefit by treatment of all members as recommended by WHO (2). Individual patient could be identified by analysing household members separately in a follow-up.

\section{CONCLUSION}

From the outcome of this study, PCR assays that employ the use of non-invasive sample collection are recommended for use in mass diagnosis, epidemiology and surveillance of lymphatic filariasis. We recommend that pooling of samples per household and other methods that could be useful in cost reduction of performing PCR assays should further be investigated.

The PCR assay utilising sputum can complement other methods used for epidemiology, mass diagnosis and surveillance of lymphatic filariasis post elimination phase.

\section{ACKNOWLEDGEMENTS}

To colleagues and the people of Malindi for their valuable inputs. Dr Ibrahim Abassi, Charles Were, Rosemary Githae, Gabriel Nzai and Paul Mwambire for their advice, technical and field work. This study was financially supported by IAEA project KEN6012 and KEN6014. This paper was published through kind permission from the Director, Kenya Medical Research Institute.

\section{REFERENCES}

1. Manson-Bahr, P.E.C. and Apted, F.I.C. Manson's Tropical Diseases $18^{\text {th }}$ edition, Published by Bailliere Tindall.NY 1984: Pp: 149-165 and 720-727.

2. Global disease elimination and eradication as public health strategies. World Health Org. Bull. 1998; 76: 1725.

3. Lindsay, S.W. and Thomas, C.J.Mapping and estimating the population at risk from lymphatic filariasis in Africa. Trans. R. Soc. Trop. Med. Hyg. 2000; 94: 37-45.

4. Wijers, D.J.B. Bancroftian filariasis in Kenya 1: Prevalence survey among dult males in the coast province. Ann. Trop. Med. Parasitol. 1977; 71:313-317.

5. Abbasi, I, Githure, J., Ochola, J.J. et al. Diagnosis of Wuchereria bancrofti infection by the polymerase chain reaction employing patient's sputum. Parasitol Res. 1999; 85: $844-849$

6. Weil, G.J., Ramzy, R.M., Chandrashekar, R., et al. Parasite antigenemia without microfilaremia in bancroftian filariasis. Am. J. Trop. Med Hyg. 1996; 55: 86-89.

7. McMahon, J. E., Marshal, T.F., Vaughan, J.P. and Abaru, D. E. Bancroftian filariasis: A comparison of microfilaria counting techniques using counting chamber, standard slide and membrane (nucleopore) filtration. Ann. Trop. Med. Parasitol. 1979; 41: 403-406.

8. Fischer, A. A., Laing, J. E., Stoeckel, J.E., and Townsend, J. J. Handbook for family planning operations research design. (1998). 2nd edition. Population Council, New York. Pp. 97-103.

9. Zhong, M., McCarthy, J., Biewert, L., et al. A polymerase chain reaction assay for detection of the parasite Wuchereria bancrofti in human blood samples. Am. J. Trop. Med. Hyg.1996; 54: 357-363.

10. Greenhalgh, T. How to read a paper: Papers that report diagnostic or screening tests. Brit. Med. J. 1997; 315: 540543.

11. Pani, S. P, Hoti, A.L., Elango, A., et al. Evaluation of the ICT whole blood antigen card test to detect infection due to nocturnally periodic Wuchereria bancrofti infections in South India. Trop. Med. Int. Health. 2000; 5: 369-363.

12. Audrey, S., Addiss, D. G., Eberhard, M. L. and Lammie, P.J. Evaluation of the whole blood filariasis ICT for short-term monitoring after antifilarial treatment. Am.J. Trop. Med. Hyg. 2000; 62: 502-503.

13. Sepkowitze, K.A. Occupationally acquired infections in health care workers. Annals. 1996; 125: 917-928.

14. Marcus R. Surveillance of health workers exposed to blood from patients infected with human immunodeficience virus. N. Engl. J. Med. 1988; 319: 1118-1123.

15. Lucena, W.A., Dhalia, R., Abath, F.G.C., et al. Diagnosis of Wuchereria bancrofti infection by the PCR using urine and day blood in Amicrofilaremic patients. Trans. R. Soc. Trop. Med. Hyg. 1998; 92: 290-293.

16. Malhotra, I, Ouma, J. H., Wamachi, A., et al. Influence of maternal filariasis on childhood infection and immunity to Wuchereria bancrofti in Kenya. Inf. Imm. 2003; 71:52315237.

17. Weerasooriya, M.V., Itoh, M., Islam, M. Z., et al. Prevalence and levels of filarial-specific urinary IgG4 among children less than five years of age and the association of antibody positivity between children and their mothers. Am. J. Trop. Hyg., 2003; 68: 465-468. 